\title{
Uptake, translocation and biotransformation kinetics of BDE-47, 6-OH-BDE-47 and 6-MeO-BDE-47 in maize (Zea mays L.)
}

\author{
Xuehui Xu a , Bei Wen ${ }^{\text {a }}$, Honglin Huang a , Sen Wang a, b, Ruixia Han ${ }^{a}$, Shuzhen Zhang a, * \\ a State Key Laboratory of Environmental Chemistry and Ecotoxicology, Research Center for Eco-Environmental Sciences, Chinese Academy of Sciences, \\ P.O. Box 2871, Beijing, 100085, China \\ ${ }^{\mathrm{b}}$ Department of Environmental Sciences, College of Urban and Environmental Sciences, Northwest University, Xi'an, 710027, China
}

\section{A R T I C L E I N F O}

\section{Article history:}

Received 4 August 2015

Received in revised form

24 October 2015

Accepted 26 October 2015

Available online 10 November 2015

\section{Keywords:}

PBDEs

OH-PBDEs

MeO-PBDEs

Biotransformation

Maize

\begin{abstract}
A B S T R A C T
This study presents a detailed kinetic investigation on the uptake, acropetal translocation and transformation of BDE-47, 6-OH-BDE-47 and 6-MeO-BDE-47 in maize (Zea mays L.) by hydroponic exposure. Root uptake followed the order: BDE-47 > 6-MeO-BDE-47 > 6-OH-BDE-47, while 6-OH-BDE-47 was the most prone to acropetal translocation. Debromination rates of BDE-47 were 1.31 and 1.46 times greater than the hydroxylation and methoxylation rates, respectively. Transformation from BDE-47 to lower brominated $\mathrm{OH} / \mathrm{MeO}-\mathrm{PBDEs}$ occurred mainly through debromination first followed by hydroxylation or methoxylation. There was no transformation from 6-OH-BDE-47 or 6-MeO-BDE-47 to PBDEs. Methylation rate of 6-OH-BDE-47 was twice as high as that of 6-MeO-BDE-47 hydroxylation, indicating methylation of 6-OH-BDE-47 was easier and more rapid than hydroxylation of 6-MeO-BDE-47. Debromination and isomerization were potential metabolic pathways for 6-OH-BDE-47 and 6-MeO-BDE-47 in maize. This study provides important information for better understanding the mechanism on plant uptake and transformation of PBDEs.
\end{abstract}

(C) 2015 Elsevier Ltd. All rights reserved.

\section{Introduction}

Polybrominated diphenyl ethers (PBDEs) have been widely used as additive flame retardants in a variety of household and industrial products for decades (de Wit, 2002). Based on the knowledge of their adverse effects on the environment and human health, some PBDEs have been included on the Stockholm Convention list of priority persistent organic pollutants, and some technical products have been banned or voluntarily withdrawn from use in some regions of the world (California State Assembly, 2003; Cox and Efthymiou, 2003). However, owing to their high volume production, long-term use, and lipophilic and persistent properties, PBDEs are still frequently detected in various environmental media (Kim et al., 2014; Newton et al., 2015) and biotic samples (Shang et al., 2013; Wang et al., 2014; Zhu et al., 2009) in the environment. Therefore, there is considerable concern about their behaviors and fates in the environment.

In addition, PBDEs have a tendency to break down into lower brominated congeners in the environment (Gandhi et al., 2011; He

\footnotetext{
* Corresponding author

E-mail address: szzhang@rcees.ac.cn (S. Zhang).
}

et al., 2006; Tokarz et al., 2008). Hydroxylated PBDEs (OH-PBDEs) and methoxylated PBDEs (MeO-PBDEs) have also been identified in various environmental media (Ueno et al., 2008; Wang et al., 2014) and biological samples (Kelly et al., 2008; Teuten et al., 2005). Their origin is far from clear, and increasing evidence has shown the existence of transformation of PBDEs to OH-PBDEs and MeO-PBDEs (Stapleton et al., 2009; Sun et al., 2013a; Wang et al., 2012). Debrominated PBDEs, OH-PBDEs and MeO-PBDEs have greater potencies for some adverse effects such as embryo developmental toxicity (Boxtel et al., 2008), genotoxicity (Ji et al., 2011) and endocrine disrupting effects (He et al., 2008; Meerts et al., 2001; Wiseman et al., 2011) than their precursor PBDEs, and may bring additional adverse influences to bear on the environment and human health; therefore their formations and behaviors in the environment have received increasing attention.

Soils represent a major sink for organic contaminants in the environment, and PBDEs have been frequently detected in soils (Tang et al., 2014; Wang et al., 2014). For example, a total concentration of PBDEs ranging between 65 and $6080 \mathrm{ng} \mathrm{kg}^{-1}$ dry weight was observed in UK and Norwegian soils in a survey of European soils (Hassanin et al., 2004). In our previous study, we identified a total of 41 PBDE congeners, with the total concentrations ranging 
from 13.9 to $13,251.2 \mathrm{ng} \mathrm{g}^{-1}$ dry weight, together with twelve $\mathrm{OH}$ PBDEs and MeO-PBDEs in the soils collected in Qingyuan country in Guangdong Province (Wang et al., 2014). Concentrations of PBDEs in plants were even reported as high as $70-5900 \mathrm{ng} \mathrm{g}^{-1}$ dry weight by a field investigation in Laizhou, China (Jin et al., 2008). The uptake, translocation and accumulation of PBDEs have been demonstrated by previous studies (Huang et al., 2011; Wang et al., 2014). Root concentration factors (RCFs) of PBDEs were found 0.02-2.18 and $0.01-1.2$ for plants uptake from e-waste soils in a pot experiment (Huang et al., 2011) and field experiment (Wang et al., 2014), respectively. Furthermore, metabolic transformation of organic contaminants in plants is an important biotransformation process in terrestrial ecosystems (Sandermann, 1994; Yu et al., 2013). Despite their high importance, studies on the behavior of PBDEs in terrestrial plants are very limited, particularly regarding the biotransformation of PBDEs, OH-PBDEs and MeO-PBDEs in plants. In our previous work, transformation of PBDEs to lower brominated PBDEs, OH-PBDEs and MeO-PBDEs in plants was observed (Huang et al., 2010; Wang et al., 2012). Sun et al. (2014) recently reported the reciprocal transformation between OH-PBDEs and the corresponding MeO-PBDEs in young whole pumpkin plants by a hydroponic experiment. Unfortunately, this study only focused on the inter-conversions between $\mathrm{MeO}-\mathrm{PBDEs}$ and corresponding $\mathrm{OH}-$ PBDEs without considering the possibility of further transformation. More importantly, there is a paucity of research on the transformation kinetics of PBDEs, OH-PBDEs and MeO-PBDEs, which is necessary to gain a thorough insight into their metabolic pathways.

The aim of this study was to investigate the uptake, translocation and biotransformation of PBDEs, OH-PBDEs and MeOPBDEs by maize. PBDEs always exist as a mixture in field soils, which brings difficulties to distinguish the debrominated products from the same PBDE congeners, originally existed in the soils. Pot experiment with soil will introduce the influences of soil micrograms on biotransformation and bring difficulties for elucidating biotransformation of PBDEs by plants. Therefore, a hydroponic experiment was conducted although it cannot entirely exclude the influences from root-associated microbes. BDE-47 is frequently detected in PBDE-contaminated soils and accumulated in plants at relatively high concentrations (Kim et al., 2014; Sun et al., 2013b). So, BDE-47 and its hydroxylated and methoxylated analogs (6-OHBDE-47 and 6-MeO-BDE-47) were selected as the target compounds, and their kinetic uptake by roots and acropetal translocation in maize were investigated. Biotransformation products within maize after exposure to BDE-47, 6-OH-BDE-47 and 6-MeOBDE-47 at different time intervals were identified. Based on the kinetic profiles of metabolic congeners and their concentrations, the metabolic pathways of BDE-47, 6-OH-BDE-47 and 6-MeO-BDE47 in maize are discussed.

\section{Material and methods}

\subsection{Chemicals}

Chemical standards of BDE-47, 6-MeO-BDE-47 and 6-OH-BDE47 (purity $>98.0 \%$, New Haven, CT, USA) were used as exposure compounds (Table S1). ${ }^{13} \mathrm{C}-\mathrm{PCB}-141$ and ${ }^{13} \mathrm{C}-6-\mathrm{OH}-\mathrm{BDE}-47$ were used as surrogate standards purchased from Cambridge Isotope Laboratory (Andover, MA, USA). A mixed standard solution of PBDEs containing 24 PBDEs through mono-to tetra-BDEs, standards of nine OH-PBDEs and standards of nine MeO-PBDEs from AccuStandard (New Haven, CT, USA) were used in the identification and quantification of the metabolites. All these compounds were analyzed in the BDE-47, 6-MeO-BDE-47 and 6-OH-BDE-47 solutions to check their purity, and the presence of diverse impurities in solutions (Table S2) did not affect the exposure experiments as well as discussion on metabolic reactions. Distilled water was used in all the experiments. Solvents, including hexanes, acetone, acetonitrile, dichloromethane (DCM) and methyl tert-butyl ether (MTBE), were of HPLC grade (Thermo fisher, MA, USA). All the other chemicals used were of analytical grade (Sinopharm Chemical Reagent Co., Ltd, BJ, China).

\subsection{Exposure experiment}

The exposure solutions of BDE-47, 6-OH-BDE-47 and 6-MeOBDE-47 were obtained by first dissolving the standard solution in acetone, and then gradually diluting with sterile half-strength Hoagland nutrient solution in bottles wrapped with aluminumfoil paper. The nominal concentrations of BDE-47, 6-OH-BDE-47 and $6-\mathrm{MeO}-\mathrm{BDE}-47$ in the exposure solutions were set at $20 \mathrm{nmol} \mathrm{L}^{-1}$. The volume of acetone in the test solutions was less than $1 \%$ o (v/v). The $\mathrm{pH}$ was adjusted to 6.5. Each solution was prepared immediately prior to exposure and mixed thoroughly to ensure complete dissolution. The concentrations of BDE-47, 6-OHBDE-47 and 6-MeO-BDE-47 in the solutions were then determined at $18.4 \pm 1.1,17.9 \pm 1.7$ and $18.9 \pm 0.9 \mathrm{nmol} \mathrm{L}^{-1}$ before exposure, respectively.

Maize (Zea mays L.) seeds were obtained from the Chinese Academy of Agricultural Sciences, Beijing, China. Prior to germination, seeds of similar size were selected and surface-sterilized in $3 \%(\mathrm{v} / \mathrm{v}) \mathrm{H}_{2} \mathrm{O}_{2}$ for $30 \mathrm{~min}$, followed by thoroughly washing with distilled water, and subsequently germinated on moist filter paper. After 4 days, uniformly (about $5 \mathrm{~cm}$ in height) germinated seedlings were transferred to glass containers containing half-strength Hoagland nutrient solution and ready for exposure after $7 \mathrm{~d}$ of cultivation.

The whole seedlings were transferred to sterile glassstoppered flasks for the exposure, which were wrapped with black paper to eliminate photolysis of the compounds. Then $150 \mathrm{~mL}$ of the test solutions of BDE-47, 6-OH-BDE-47 and 6-MeOBDE-47 were added individually. Treatments with maize seedlings in $150 \mathrm{~mL}$ of sterile half-strength Hoagland nutrient solution were set as untreated controls to monitor possible cross contamination, and treatments with $150 \mathrm{~mL}$ test solution but no plants were set as unplanted controls to monitor any possible loss. Pots were kept in a controlled environment growth chamber at a light intensity of $250 \mu \mathrm{mol} \mathrm{m}^{-2} \mathrm{~s}^{-1}$ provided by supplementary illumination with a photoperiod of $14 \mathrm{~h}$ each day, at a $25 / 20^{\circ} \mathrm{C}$ day/night temperature regime and a relative humidity of $80 \%$. Approximately $20 \mathrm{~mL} \mathrm{~d}^{-1}$ of sterile half-strength Hoagland nutrient solution saturated with oxygen was injected into each container to compensate for transpiration losses. Maize seedlings were harvested at intervals of 3 , $6,12,24,48,72$ and $96 \mathrm{~h}$. At the end of the exposure, unplanted and untreated controls were sampled. All the samples were prepared in triplicate in separate containers including the ones for different time intervals.

The roots of samples were first thoroughly rinsed with deionized water and blotted with tissue paper, and maize seedlings were separated into roots and shoots for the subsequent analysis. All the harvested plant samples were freeze-dried at $-50{ }^{\circ} \mathrm{C}$ for $48 \mathrm{~h}$ in a lyophilizer (FD-1, Boyikang Instrument Ltd, Beijing, China), weighed and stored at $-20{ }^{\circ} \mathrm{C}$ for analysis. The subsequent calculations were therefore based on dry weight.

\subsection{Sample extraction and analysis}

To prevent photolysis of PBDEs, OH-PBDEs and MeO-PBDEs, all the glasses used for sample extraction and cleanup were wrapped with aluminum-foil paper. Before extraction, surrogate standards of 
${ }^{13} \mathrm{C}-\mathrm{PCB}-141$ and ${ }^{13} \mathrm{C}-6-\mathrm{OH}-\mathrm{BDE}-47$ (20 ng of each) were added to the samples, and kept for $1 \mathrm{~h}$. Extraction and analysis of PBDEs and MeO-PBDEs in plant samples were based on the methods of López et al. (2009) and Wang et al. (2011b). An Agilent 7890 GC-MS (5975 inert) (Agilent, Palo Alto, CA, USA) and a DB-5MS column (30 $\mathrm{m} \times 0.32 \mathrm{~mm}$ i.d., $0.25 \mu \mathrm{m}$ film thickness, J \& W Scientific, Folsom, CA, USA) were used for the analysis of PBDEs and MeOPBDEs, respectively (Wang et al., 2011b). For the determination of $\mathrm{OH}-\mathrm{PBDEs}$, The extraction and cleanup procedures were based on the methods described in our previous research (Wang et al., 2011a) with minor modifications. A UPLC-MS/MS system was used to detect and quantify the OH-PBDEs. Chromatographic separation of OH-PBDEs was performed on an UPLC (Waters ACQUITY UPLC system, Waters, Milford, MA, USA). Reversed-phase chromatography was performed by a Waters ACQUITY UPLC BEH $C_{18}$ column $(2.1 \mathrm{~mm} \times 100 \mathrm{~mm}, 1.7 \mu \mathrm{m}$ particle size, Waters, Milford, MA, USA) maintained at $40^{\circ} \mathrm{C}$. Mass spectrometry analysis was carried out using a Waters Xevo TQ MS triple quadrupole mass spectrometer equipped with an ESI source (Waters, Milford, MA, USA). Details of sample extraction and analysis are provided in the supplementary material.

\subsection{Quality control and quality assurance}

Quality control was done by regular analyses of the procedural blanks, blind duplicate samples, and random injection of solvent blanks and standards. Quality assurance was guaranteed by the addition of surrogate standards and the standards of PBDEs, OHPBDEs and MeO-PBDEs individually to the blank plant samples. Recoveries were $72.3-97.1 \%$ for ${ }^{13} \mathrm{C}-\mathrm{PCB}-141$ and $77.4-96.5$ for ${ }^{13} \mathrm{C}$ 6-OH-BDE-47, and 79.8-110.5\%, 70.2-91.3\% and $66.2-99.7 \%$ for PBDEs, OH-PBDEs and MeO-PBDEs, respectively. The limits of detection (LODs) defined as a signal-to-noise ratio $(\mathrm{S} / \mathrm{N})$ of 3 were in the range of $25-52 \mathrm{pg} \mathrm{g}^{-1}$ for PBDEs, $39-83 \mathrm{pg} \mathrm{g}^{-1}$ for MeOPBDEs and $50-100 \mathrm{pg} \mathrm{g}^{-1}$ for OH-PBDEs in the plant samples $(n=6)$, respectively. Details of the LODs and matrix spike recoveries for the individual PBDE, MeO-PBDE and OH-PBDE congeners are provided in Table S3 of the supplementary material.

\subsection{Modeling}

A pseudo-first order kinetic model was applied to assess the metabolism kinetics of BDE-47, 6-OH-BDE-47 and 6-MeO-BDE-47 inside maize, which can be expressed as follows:

$q_{\mathrm{t}}=q_{\mathrm{m}}[1-\exp (-k \mathrm{t})]$ where $q_{\mathrm{m}}$ and $q_{\mathrm{t}}$ (pmol pot ${ }^{-1}$ ) are the maximum and the amount of each kind of metabolites generated in maize (the sum of respective debromination, hydroxylation, methoxylation, methylation and isomerization metabolites in maize roots and shoots from one pot) over the exposure time $t(\mathrm{~h})$, respectively, and $k\left(\mathrm{~h}^{-1}\right)$ is the metabolism rate constant. The data for the amounts of each kind of metabolites generated in maize were plotted in the form of $q_{\mathrm{t}}$ versus $\mathrm{t}$ for determining first-order kinetics for BDE-47, 6-MeOBDE-47 and 6-OH-BDE-47, respectively. The fitting parameters were calculated with Origin 8.0 software (OriginLab Corporation).

\subsection{Data analysis}

All data were subjected to statistical analysis using Microsoft Excel 2010 and Origin 8.0 software. Means and standard deviation were calculated for triplicate samples and the results were expressed on a dry weight basis. A T-normality test was conducted for the obtained data before parametric statistics, and the result showed that the data fitted normal distribution. One-way analysis of variance with Duncan's multiple-comparison test was used to assess differences among samples at $p<0.05$.

\section{Results and discussion}

\subsection{Uptake and translocation of $\mathrm{BDE}-47,6-\mathrm{OH}-\mathrm{BDE}-47$ and 6-MeO- BDE-47 by maize}

Time-dependent accumulation of BDE-47, 6-OH-BDE-47 and 6MeO-BDE-47 in maize roots and shoots is displayed in Fig. 1. There was a similar variation tendency for the accumulations of BDE-47 and 6-MeO-BDE-47 in maize, increasing initially until the exposure times of $6 \mathrm{~h}$ and $24 \mathrm{~h}$ for roots and shoots, respectively, and then decreasing. The concentrations of BDE-47 and 6-MeOBDE-47 in roots were comparable, while the concentrations of 6 MeO-BDE-47 in shoots were 1.6-5.1 times as high as those of BDE-47. However, distinctly different concentration changes over time were observed for 6-OH-BDE-47 accumulation in maize. The highest concentration of 6-OH-BDE-47 in maize roots was observed at the time of first sampling and then decreased with increasing time; whereas its concentration in shoots increased continuously starting at the exposure time of $24 \mathrm{~h}$. Another difference is that the concentration of 6-OH-BDE-47 in maize roots and shoots was approximately 10-100 fold lower than those of BDE-47 and 6$\mathrm{MeO}-\mathrm{BDE}-47$. In order to compare their uptake abilities, root concentration factors (RCFs) were calculated as the ratio of the concentrations in maize roots to the concentrations in the exposure solutions. The average RCF values were in the following order: BDE-
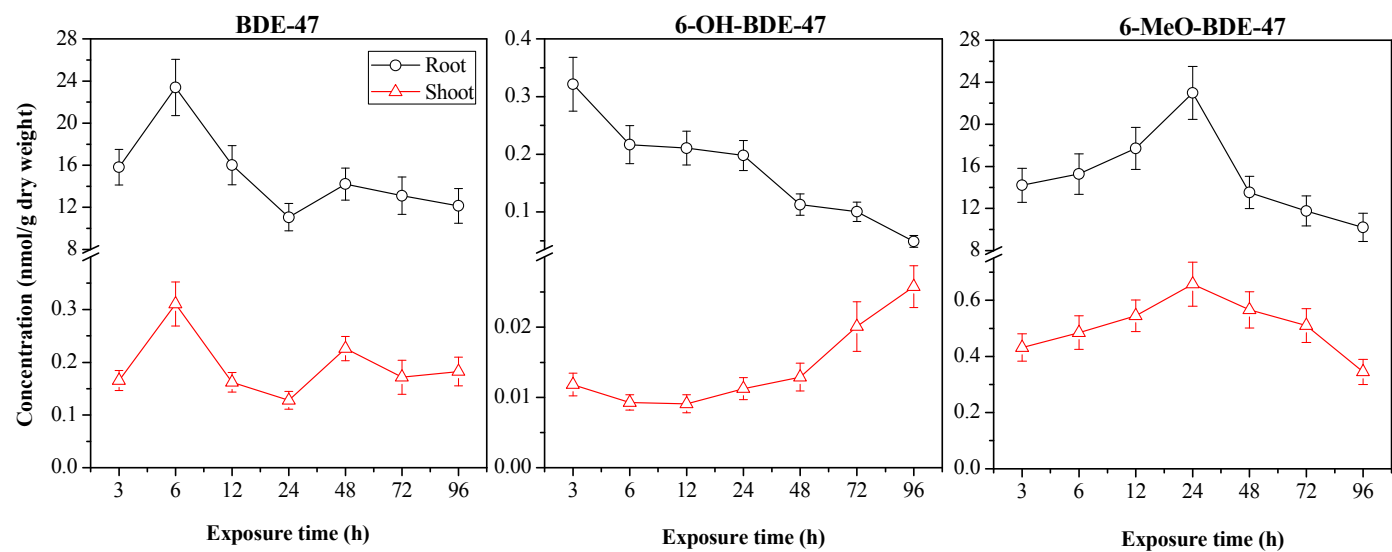

Fig. 1. The concentrations of BDE-47, 6-OH-BDE-47 and 6-MeO-BDE-47 in maize roots and shoots. 
$47>6-\mathrm{MeO}-\mathrm{BDE}-47>6-\mathrm{OH}-\mathrm{BDE}-47$, which was consistent with the previous observations in field contamination investigations (Sun et al., 2013b; Wang et al., 2014). A significant positive correlation existed between the values of $\log \mathrm{RCF}$ and $\log K_{\mathrm{ow}}\left(\mathrm{R}^{2}=0.91\right.$, $p<0.0001$ ) (Fig. S1 A), indicating that hydrophobicity determines plant uptake of BDE-47, 6-OH-BDE-47 and 6-MeO-BDE-47 and suggesting that partitioning is the key mechanism for their plant uptake (Chiou et al., 2001; Wang et al., 2011c).

The accumulations of BDE-47, 6-OH-BDE-47 and 6-MeO-BDE-47 in shoots indicated their acropetal translocation in maize. Translocation factors (TF, ng g ${ }^{-1}$ shoot/ng $\mathrm{g}^{-1}$ root on dry weight basis) were calculated, and the average TF values followed the order: 6OH-BDE-47 > 6-MeO-BDE-47 > BDE-47, which had a significantly negative correlation with their $\log K_{\text {ow }}$ values $\left(R^{2}=0.44, p<0.001\right)$ (Fig. S1 B). There were analog-specific differences in acropetal translocation of BDE-47, 6-OH-BDE-47 and 6-MeO-BDE-47 in maize. The lower $\log K_{\mathrm{ow}}$ value leads to much easier root-to-shoot translocation of 6-OH-BDE-47 than those of BDE-47 and 6-MeO$\mathrm{BDE}-47$. A reasonable explanation is that the presence of the hydroxy group in 6-OH-BDE-47 increases its polarity and water solubility and renders it more prone to transfer from roots to shoots than either the corresponding unsubstituted BDE-47 or 6-MeOBDE-47 (Grimm et al., 2013; Li et al., 2011; Malmvärn et al., 2008; Su et al., 2014). Studies have confirmed that OH-PBDEs have higher toxicity than their parent PBDEs and corresponding MeO-PBDEs (Xu et al., 2015). This quicker uptake and more pronounced rootto-shoot translocation would lead to more serious phytotoxicity for OH-PBDEs, to which we should pay particular attention.

\subsection{Metabolic products of BDE-47, 6-OH-BDE-47 and 6-MeO-BDE- 47 in maize}

Debrominated, hydroxylated and methoxylated metabolites were detected in tissues of maize after exposure to BDE-47, 6-OHBDE-47 and 6-MeO-BDE-47 (Fig. 2), while none of them was found in the untreated and unplanted controls, strongly suggesting that it was mainly the maize that transformed BDE-47, 6-OH-BDE-47 and 6 -MeO-BDE-47. The mass balance of each compound was calculated and the recoveries of BDE-47 and 6-MeO-BDE-47 fluctuated around $100 \%$ at each time point (Table 1 ), suggesting their losses from volatilization to the air and sorption on the surface of the exposure container were negligible. However, the recovery of 6OH-BDE-47 was $80 \%$ at the first sampling time and then decreased to $38 \%$ at the end of the experiment (Table 1). Considering the higher polarity and water solubility of 6-OH-BDE-47 compared to BDE-47 and 6-MeO-BDE-47 (Table S1), lower recoveries of 6-OH-BDE-47 should not be due to its losses from the exposure solution. It is therefore reasonable to expect the existence of some unknown biotransformation metabolites in maize after exposure to 6-OH-BDE-47, such as bromophenol and diOH-PBDEs, which have been detected as metabolites of OH-PBDEs in rat liver microsomes (Lai and Cai, 2012). The biotransformation extent of BDE-47, 6-OH-BDE-47 and 6-MeO-BDE-47 in maize was $1.16-8.79 \%, 2.36-26.3 \%$ and $0.087-1.30 \%$ for different time intervals, respectively.

Six debrominated, five hydroxylated and five methoxylated metabolites were detected in maize exposed to BDE-47 (Fig. 2A). The total amount of debrominated metabolites was higher than those of hydroxylated and methoxylated metabolites. BDE-28 was found to be the dominant product in maize after exposure for $3 \mathrm{~h}$, while the lower debrominated metabolites, BDE-15, BDE-3, and bromine atom rearrangement metabolites, BDE-12/13, BDE-10, BDE-2, were detected after exposure for $6 \mathrm{~h}$. These suggested that debromination of BDE-47 took place step-by-step and preferentially occurred at ortho-positions. Wang et al. (2012) and Sun et al. (2013a) have also detected OH-PBDEs and MeO-PBDEs as biotransformation products of BDE-47 in maize and pumpkin, respectively, but both failed to answer the question whether the $\mathrm{MeO}-\mathrm{PBDEs}$ were formed by methylation of the OH-PBDE metabolites or direct methoxylation of the parent PBDEs. In this study, the hydroxylated metabolites in maize were found after exposure for $3 \mathrm{~h}$ (Fig. 2A-b), whereas the methoxylated metabolites were detected after exposure for $6 \mathrm{~h}$ (Fig. 2A-c). Such differences indicated that the formation of hydroxylated metabolites occurred earlier than that of methoxylated metabolites from BDE-47, and suggested that MeO-PBDEs in maize were formed by the methylation of the OH-PBDEs.

In the BDE-47 exposed maize, besides 6-OH-BDE-47, the lower brominated hydroxylated metabolites, $3^{\prime}-\mathrm{OH}-\mathrm{BDE}-28$ and $2^{\prime}-\mathrm{OH}-$ BDE-3, were detected as the dominant species, followed by hydroxyl group or bromine atom rearrangement products of 5-OHBDE-47 and 2'-OH-BDE-68 (Fig. 2A-b). 6-MeO-BDE-47 was the predominant methoxylated metabolite in maize roots and shoots, followed by 5-MeO-BDE-47 and 4'-MeO-BDE-49 of methoxyl group or bromine atom rearrangement products, and then $3^{\prime}-\mathrm{MeO}-\mathrm{BDE}-$ 28 and $2^{\prime}$-MeO-BDE-3 of the lower brominated methoxylated metabolites (Fig. 2A-c). Lower brominated hydroxylated and methoxylated metabolites may be formed through hydroxylation and methoxylation of the PBDE debrominated products or debromination of the hydroxylated and methoxylated products. However, it is still unclear which one is the main transformation pathway.

In order to elucidate the formation pathways of lower brominated hydroxylated and methoxylated metabolites, the metabolic products of 6-OH-BDE-47 and 6-MeO-BDE-47 in maize were determined. Neither BDE-47 nor lower brominated PBDEs was detected in tissues of maize after exposure to 6-OH-BDE-47 or 6$\mathrm{MeO}-\mathrm{BDE}-47$. 6-MeO-BDE-47 was detected for 6-OH-BDE-47 exposure and 6-OH-BDE-47 was found for 6-MeO-BDE-47 exposure (Fig. 2B-a, C-b), suggesting the inter-conversion between 6-MeOBDE-47 and 6-OH-BDE-47 by maize. Besides their inter-conversion, five methoxylated metabolites (2'-MeO-BDE-68, 5-MeO-BDE-47, 3'-MeO-BDE-28, 3'-MeO-BDE-7 and 2'-MeO-BDE-3) and four hydroxylated metabolites (5-OH-BDE-47, 2'-OH-BDE-68, 3'-OH-BDE28 and $\left.2^{\prime}-\mathrm{OH}-\mathrm{BDE}-3\right)$ were detected in the tissues of maize exposed to 6-OH-BDE-47 and 6-MeO-BDE-47, respectively (Fig. 2B-a and Cb). Two lower brominated hydroxylated metabolites, $3^{\prime}-\mathrm{OH}-\mathrm{BDE}-$ 28 and $2^{\prime}-\mathrm{OH}-\mathrm{BDE}-3$, and three lower brominated methoxylated metabolites, 3'-MeO-BDE-28, 3'-MeO-BDE-7 and 2'-MeO-BDE-3, were detected in the tissues of maize exposed to 6-OH-BDE-47 and 6-MeO-BDE-47, respectively (Fig. 2B-b and C-a), suggesting that lower brominated hydroxylated and methoxylated metabolites could be formed through debromination of OH-PBDEs and $\mathrm{MeO}-$ PBDEs. Similar results of OH-tetraBDE formation from $\mathrm{OH}-$ pentaBDE were reported previously (Wan et al., 2009). The isomers of 6-OH-BDE-47 and 6-MeO-BDE-47 resulting from the rearrangement of bromine atoms, hydroxyl or methoxyl groups were also detected in maize. For example, 3-OH-BDE-47, 5-OH-BDE-47 and $2^{\prime}-\mathrm{OH}-\mathrm{BDE}-68$ were isomers of $6-\mathrm{OH}-\mathrm{BDE}-47$, while $2^{\prime}-\mathrm{MeO}-$ BDE-68 was an isomer of 6-MeO-BDE-47 (Fig. 2B-b and C-a). Simultaneous detections of $2^{\prime}-\mathrm{OH}-\mathrm{BDE}-68,5-\mathrm{OH}-\mathrm{BDE}-47,3-\mathrm{OH}-$ BDE-47 and 6-OH-BDE-47, 2'-MeO-BDE-68 and 6-MeO-BDE-47 in mice (Qiu et al., 2007), fish (Munschy et al., 2010) and maize (Wang et al., 2012) have been reported, supporting our observation on bioisomerization of 6-OH-BDE-47 and 6-MeO-BDE-47 in maize.

\subsection{Metabolic kinetics of $B D E-47,6-O H-B D E-47$ and 6-MeO-BDE- 47 in maize}

Knowledge of the transformation kinetics is necessary to 

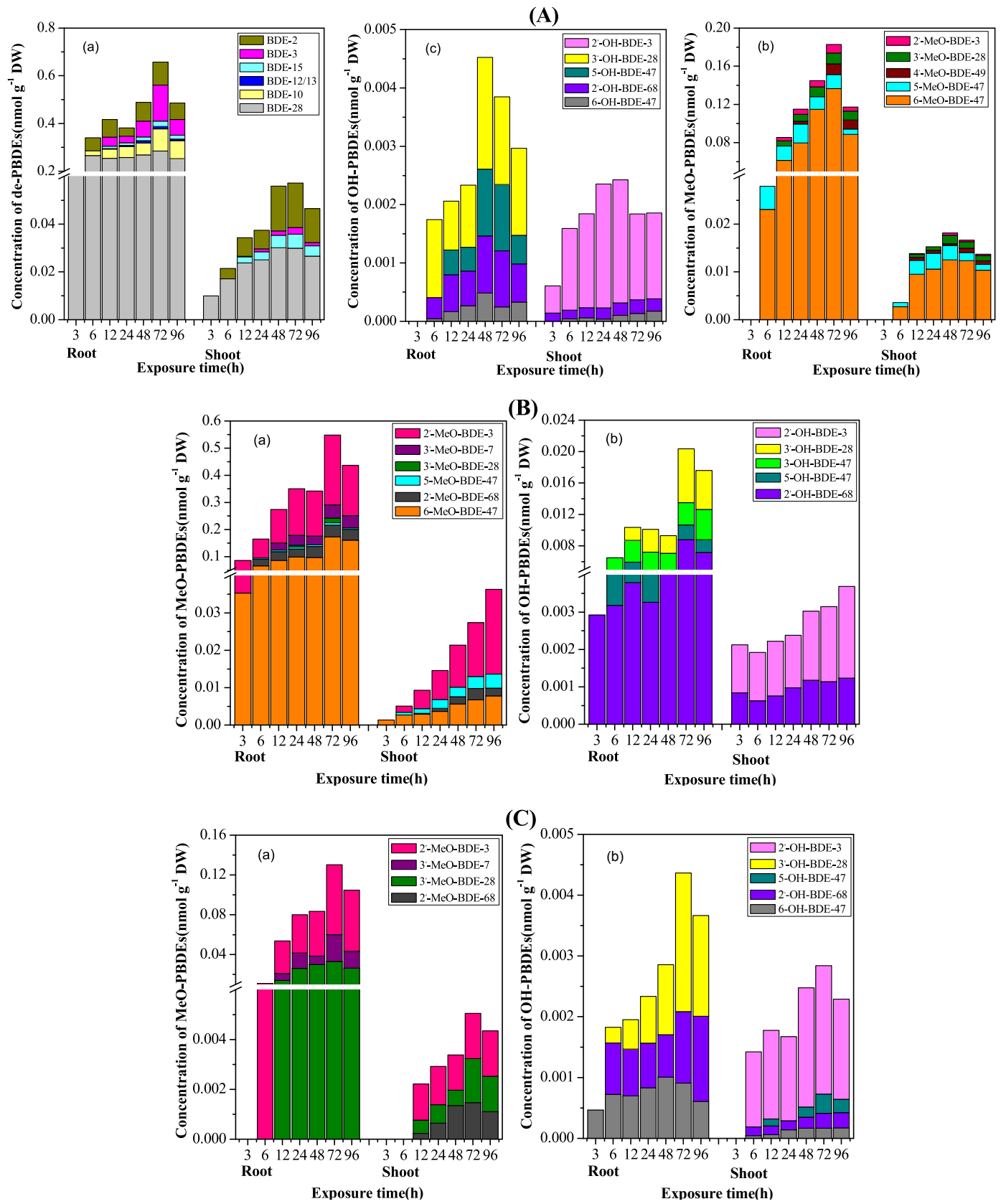

Fig. 2. The concentrations of metabolic products in maize exposed to (A) BDE-47, (B) 6-OH-BDE-47 and (C) 6-MeO-BDE-47.

quantitatively assess the transformation processes of BDE-47, 6OH-BDE-47 and 6-MeO-BDE-47 in maize. The amounts of different types of metabolic products (debrominated, methoxylated, hydroxylated and isomerized, respectively) generated in maize after exposure at different time intervals were calculated and the results are provided in Fig. S2 in the supplementary material. The data fitted well with the pseudo-first order kinetic model with high $\mathrm{R}^{2}$ values $(0.9128-0.9845)$ and low mean weighted square errors (Table 2). From the fitting results we can see that the values of transformation rate constant $(k)$ and the maximum amount of metabolites $\left(q_{m}\right)$ generated for BDE-47 debromination were significantly higher than those of its methoxylation and hydroxylation, suggesting that debromination of BDE-47 was easier than its methoxylation and hydroxylation. Moreover, the debromination rate constant of BDE-47 was 5.1 and 2.7 times as high as those of 6$\mathrm{OH}-\mathrm{BDE}-47$ and 6-MeO-BDE-47, respectively, suggesting that debromination of BDE-47 was faster than debromination of 6-OHBDE-47 and 6-MeO-BDE-47.

The $q_{m}$ and $k$ values of 6-OH-BDE-47 methylation were 40.7 and 2.8 times as high as those of $6-\mathrm{OH}-\mathrm{BDE}-47$ debromination, respectively, while the $q_{m}$ and $k$ values of 6-MeO-BDE-47 debromination were 10.3 and 1.4 times as high as those of 6-MeO-BDE-47 hydroxylation. These suggested that methylation and debromination are the main transformation pathways of 6-OH-BDE-47 and 6MeO-BDE-47, respectively. Though the debromination of hydroxylated and methoxylated products was demonstrated, the higher $q_{m}$ and $k$ values of BDE-47 debromination compared with those of 6-OH-BDE-47 and 6-MeO-BDE-47 (Table 2) strongly suggested that the formation of lower brominated hydroxylated and methoxylated metabolites from BDE-47 mainly followed the pathway of debromination first and then hydroxylation and methoxylation. The rate of transformation from 6-OH-BDE-47 to MeO-PBDEs was twice as 
Table 1

Mass balances of BDE-47, 6-OH-BDE-47 and 6-MeO-BDE-47 in the experiment.

\begin{tabular}{|c|c|c|c|c|c|c|c|c|c|}
\hline \multirow[t]{2}{*}{ Compounds } & \multirow[t]{2}{*}{$\mathrm{T}(\mathrm{h})^{c}$} & \multirow[t]{2}{*}{ Solution (\%) } & \multicolumn{2}{|l|}{ Accumulation } & \multicolumn{4}{|l|}{ Metabolism } & \multirow[t]{2}{*}{ Recovery (\%) } \\
\hline & & & Root (\%) & Shoot (\%) & Debromination (\%) & Methoxylation (\%) & Hydroxylation (\%) & Isomerization (\%) & \\
\hline \multirow[t]{7}{*}{ BDE-47 } & 3 & $14.8 \pm 1.1$ & $93.7 \pm 13.1$ & $1.96 \pm 0.08$ & $1.15 \pm 0.2$ & N.D. ${ }^{a}$ & $0.007 \pm 0.001$ & $-{ }^{b}$ & $111.6 \pm 13.2$ \\
\hline & 6 & $8.50 \pm 0.5$ & $100.2 \pm 9.8$ & $4.01 \pm 0.7$ & $2.32 \pm 0.3$ & $0.21 \pm 0.07$ & $0.031 \pm 0.04$ & $-{ }^{b}$ & $115.3 \pm 12.7$ \\
\hline & 12 & $2.55 \pm 0.1$ & $95.2 \pm 10.4$ & $2.06 \pm 0.1$ & $2.92 \pm 0.08$ & $0.71 \pm 0.1$ & $0.033 \pm 0.08$ & $-{ }^{b}$ & $103.5 \pm 10.9$ \\
\hline & 24 & $2.27 \pm 0.2$ & $81.1 \pm 6.3$ & $2.02 \pm 0.1$ & $3.39 \pm 0.5$ & $1.08 \pm 0.2$ & $0.054 \pm 0.1$ & $-{ }^{b}$ & $89.9 \pm 8.7$ \\
\hline & 48 & $2.51 \pm 0.1$ & $106.0 \pm 9.1$ & $4.31 \pm 0.3$ & $5.76 \pm 0.7$ & $1.74 \pm 0.4$ & $0.090 \pm 0.07$ & $-{ }^{b}$ & $120.4 \pm 15.3$ \\
\hline & 72 & $2.14 \pm 0.4$ & $110.0 \pm 9.9$ & $4.26 \pm 0.6$ & $6.94 \pm 0.3$ & $1.95 \pm 0.1$ & $0.078 \pm 0.02$ & $-{ }^{b}$ & $125.3 \pm 13.8$ \\
\hline & 96 & $2.61 \pm 0.3$ & $98.0 \pm 8.7$ & $4.92 \pm 0.4$ & $5.98 \pm 0.6$ & $1.51 \pm 0.2$ & $0.079 \pm 0.03$ & $-{ }^{b}$ & $113.1 \pm 11.7$ \\
\hline \multirow[t]{7}{*}{ 6-OH-BDE-47 } & 3 & $69.1 \pm 7.1$ & $7.91 \pm 0.9$ & $0.61 \pm 0.04$ & $0.07 \pm 0.002$ & $2.17 \pm 0.6$ & $-{ }^{b}$ & $0.12 \pm 0.05$ & $80.0 \pm 9.2$ \\
\hline & 6 & $24.7 \pm 3.4$ & $5.92 \pm 1.1$ & $0.61 \pm 0.06$ & $0.09 \pm 0.004$ & $4.85 \pm 1.0$ & $-^{b}$ & $0.22 \pm 0.03$ & $36.4 \pm 5.1$ \\
\hline & 12 & $14.2 \pm 2.3$ & $5.51 \pm 0.7$ & $0.60 \pm 0.1$ & $0.14 \pm 0.01$ & $7.79 \pm 0.7$ & $-{ }^{b}$ & $0.28 \pm 0.03$ & $28.5 \pm 4.2$ \\
\hline & 24 & $11.4 \pm 1.9$ & $5.89 \pm 0.5$ & $0.82 \pm 0.09$ & $0.19 \pm 0.03$ & $11.5 \pm 1.4$ & $-{ }^{b}$ & $0.29 \pm 0.05$ & $30.1 \pm 3.3$ \\
\hline & 48 & $10.1 \pm 1.7$ & $3.58 \pm 0.2$ & $1.05 \pm 0.2$ & $0.22 \pm 0.02$ & $12.6 \pm 2.3$ & $-{ }^{b}$ & $0.32 \pm 0.04$ & $27.8 \pm 2.9$ \\
\hline & 72 & $5.87 \pm 1.0$ & $4.08 \pm 0.7$ & $2.06 \pm 0.2$ & $0.49 \pm 0.06$ & $25.1 \pm 3.1$ & $-{ }^{b}$ & $0.67 \pm 0.1$ & $38.3 \pm 3.7$ \\
\hline & 96 & $6.45 \pm 0.9$ & $2.41 \pm 0.3$ & $3.30 \pm 0.4$ & $0.54 \pm 0.04$ & $24.6 \pm 2.7$ & $-^{b}$ & $0.73 \pm 0.1$ & $38.0 \pm 5.2$ \\
\hline \multirow[t]{7}{*}{ 6-MeO-BDE-47 } & 3 & $15.1 \pm 4.4$ & $99.2 \pm 8.8$ & $5.17 \pm 0.9$ & N.D. ${ }^{a}$ & $-{ }^{b}-$ & N.D. ${ }^{a}$ & N.D. ${ }^{a}$ & $119.4 \pm 14.4$ \\
\hline & 6 & $11.0 \pm 2.3$ & $88.2 \pm 9.2$ & $5.61 \pm 1.3$ & $0.06 \pm 0.001$ & $-^{b}$ & $0.027 \pm 0.005$ & N.D. ${ }^{a}$ & $104.9 \pm 10.7$ \\
\hline & 12 & $4.17 \pm 0.7$ & $98.4 \pm 11.7$ & $6.52 \pm 2.0$ & $0.32 \pm 0.02$ & $-{ }^{b}$ & $0.032 \pm 0.004$ & $0.003 \pm 0.001$ & $109.4 \pm 12.6$ \\
\hline & 24 & $2.53 \pm 0.3$ & $101.8 \pm 5.3$ & $8.78 \pm 1.5$ & $0.53 \pm 0.1$ & $-^{b}$ & $0.037 \pm 0.002$ & $0.009 \pm 0.003$ & $113.7 \pm 8.9$ \\
\hline & 48 & $6.57 \pm 0.5$ & $99.5 \pm 8.1$ & $9.62 \pm 2.1$ & $0.65 \pm 0.3$ & $-^{b}$ & $0.063 \pm 0.01$ & $0.023 \pm 0.007$ & $116.4 \pm 9.4$ \\
\hline & 72 & $5.25 \pm 0.3$ & $93.6 \pm 10.6$ & $9.03 \pm 1.1$ & $1.01 \pm 0.5$ & $-^{b}$ & $0.085 \pm 0.02$ & $0.026 \pm 0.004$ & $109.0 \pm 11.3$ \\
\hline & 96 & $5.79 \pm 0.4$ & $104.6 \pm 7.3$ & $9.64 \pm 1.6$ & $1.17 \pm 0.2$ & $-{ }^{b}$ & $0.101 \pm 0.02$ & $0.031 \pm 0.002$ & $121.4 \pm 10.1$ \\
\hline
\end{tabular}

high as that from 6-MeO-BDE-47 to OH-PBDEs, suggesting that 6OH-BDE-47 was more prone to transform in maize than 6-MeOBDE-47. Additionally, though the isomerization rates of 6-OH-BDE47 and 6-MeO-BDE-47 were low, coexistence of their isomers in biotic (Lacorte and Ikonomou, 2009; Malmvärn et al., 2008; Qiu et al., 2009) and abiotic (Kelly et al., 2008; Wang et al., 2014; Zhang et al., 2012) media suggested the formation of OH-PBDEs and MeO-PBDEs, through isomerization could not be ignored.

\subsection{Metabolic pathways of BDE-47, 6-OH-BDE-47 and 6-MeO- $B D E-47$ in maize}

Debromination, rearrangement of bromine atoms, hydroxylation and methoxylation of BDE-47 were detected to occur in maize, with debromination as the most dominant reaction. The debrominated products of BDE-47 were formed via the removal of a bromine atom at ortho-positions (BDE-28, BDE-15) and para-positions (BDE-2, BDE-3), and bromine atom rearrangement (BDE-12/ 13, BDE-10). Detection of 5-OH-BDE-47, 6-OH-BDE-47 and 2'-OHBDE-68 in maize suggested that hydroxylation of PBDEs occurred via direct insertion of a hydroxyl group into the biphenyl backbone accompanied with a bromine shift. Methoxylated metabolites were mainly formed through methylation of hydroxylated metabolites. The lower brominated OH-PBDEs and MeO-PBDEs were the results of hydroxylation and methoxylation of the debrominated products of BDE-47 and debromination of hydroxylated and methoxylated products of BDE-47, with the former as the main pathway.

Debromination, isomerization and methlation/demethlation of 6-OH-BDE-47 and 6-MeO-BDE-47 happened in maize. Previous researches have reported the reciprocal transformation between OH-PBDEs and the corresponding MeO-PBDEs in young whole pumpkin plants (Sun et al., 2014) and biotransformation of $\mathrm{OH}-$ pentaBDE to OH-tetraBDE in mitochondria (Wan et al., 2009), which were consistent with the results of this study. $3^{\prime}-\mathrm{OH}-\mathrm{BDE}-28$ and $2^{\prime}$-OH-BDE-3, 2'-MeO-BDE-3, 3'-MeO-BDE-28 and $3^{\prime}-\mathrm{MeO}-$ BDE-7 were the debromination products of 6-OH-BDE-47 and 6MeO-BDE-47, respectively. Furthermore, 2'-OH-BDE-68, 5-OHBDE-47, 3-OH-BDE-47 and 2'-MeO-BDE-68 were the isomerized products formed via hydroxyl/methoxyl group shift and bromine atom rearrangement in the backbone of 6-OH-BDE-47 and 6-MeOBDE-47, respectively. Besides inter-conversion between 6-OH-BDE47 and $6-\mathrm{MeO}-\mathrm{BDE}-47$, inter-conversions between their debrominated and isomerized metabolites, for example between $3^{\prime}-\mathrm{OH}-$ BDE-28 and 3'-MeO-BDE-28, 2'-OH-BDE-68 and 2'-MeO-BDE-68,

Table 2

Fitting parameters for pseudo-first order kinetic model in the different types of metabolisms of BDE-47, 6-OH-BDE-47 and 6-MeO-BDE-47 in maize.

\begin{tabular}{|c|c|c|c|c|c|c|}
\hline Compounds & Metabolism $^{a}$ & $q_{\mathrm{m}}\left(\mathrm{pmol} \mathrm{pot}^{-1}\right)^{b}$ & $k\left(\mathrm{~h}^{-1}\right)^{c}$ & $\mathrm{R}^{2}$ & P value & $\mathrm{MWSE}^{d}$ \\
\hline \multirow[t]{3}{*}{ BDE-47 } & Debromination & $249 \pm 19.3$ & $0.051 \pm 0.010 \mathrm{e}$ & 0.9378 & $<0.0001$ & 0.009 \\
\hline & Methoxylation & $70.8 \pm 7.62$ & $0.039 \pm 0.012 d$ & 0.9202 & $<0.0001$ & 0.027 \\
\hline & Hydroxylation & $3.21 \pm 0.21$ & $0.035 \pm 0.010 \mathrm{~cd}$ & 0.9542 & $<0.0001$ & 0.011 \\
\hline \multirow[t]{3}{*}{ 6-OH-BDE-47 } & Debromination & $4.96 \pm 1.23$ & $0.010 \pm 0.005 a$ & 0.9333 & $<0.0001$ & 0.013 \\
\hline & Methylation & $202 \pm 12.2$ & $0.028 \pm 0.004 c$ & 0.9845 & $<0.0001$ & 0.003 \\
\hline & Isomerization & $6.89 \pm 2.12$ & $0.020 \pm 0.007 b$ & 0.9271 & $<0.0001$ & 0.022 \\
\hline \multirow[t]{3}{*}{ 6-MeO-BDE-47 } & Debromination & $51.7 \pm 6.23$ & $0.019 \pm 0.008 b$ & 0.9245 & $<0.0001$ & 0.037 \\
\hline & Hydroxylation & $5.01 \pm 1.05$ & $0.014 \pm 0.007 \mathrm{ab}$ & 0.9479 & $<0.0001$ & 0.009 \\
\hline & Isomerization & $2.29 \pm 0.59$ & $0.010 \pm 0.007 a$ & 0.9128 & $<0.001$ & 0.044 \\
\hline
\end{tabular}

a Metabolism types of each exposure compound.

b Calculated data from the model.

c Different letters represent significant differences between rates of metabolisms for the exposure compounds $(P<0.05$; Duncan's test).

${ }^{d}$ Mean weighted square error, equal to $1 / v \sum\left[\left(q_{\exp }-q_{\mathrm{cal}}\right)^{2} / q^{2}\right.$ exp $]$, where $v$ is the amount of freedom; $v=N-2$ for Eq. (1) (Wen et al., 2011). 


\section{(A)}

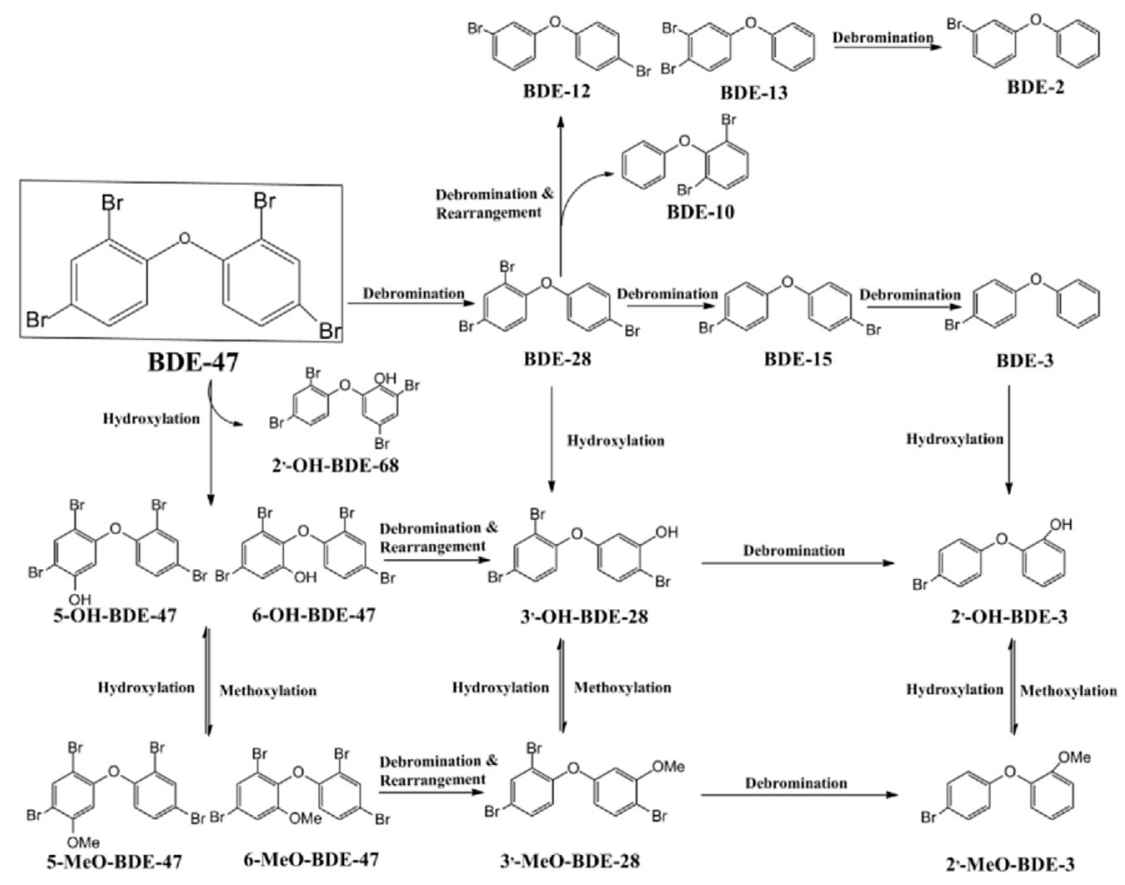

(B)

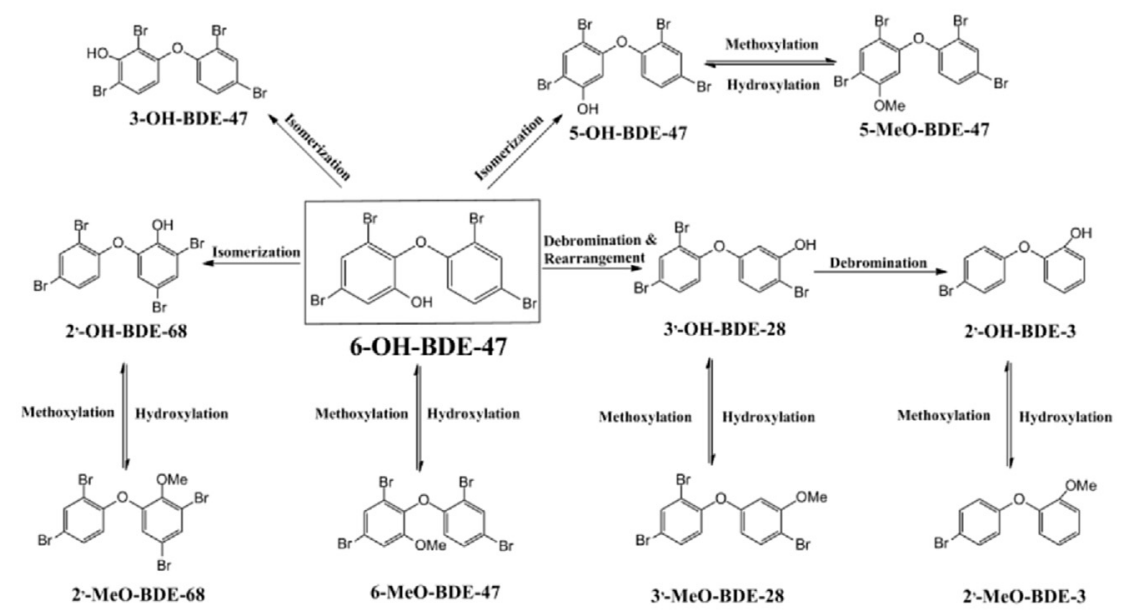

(C)

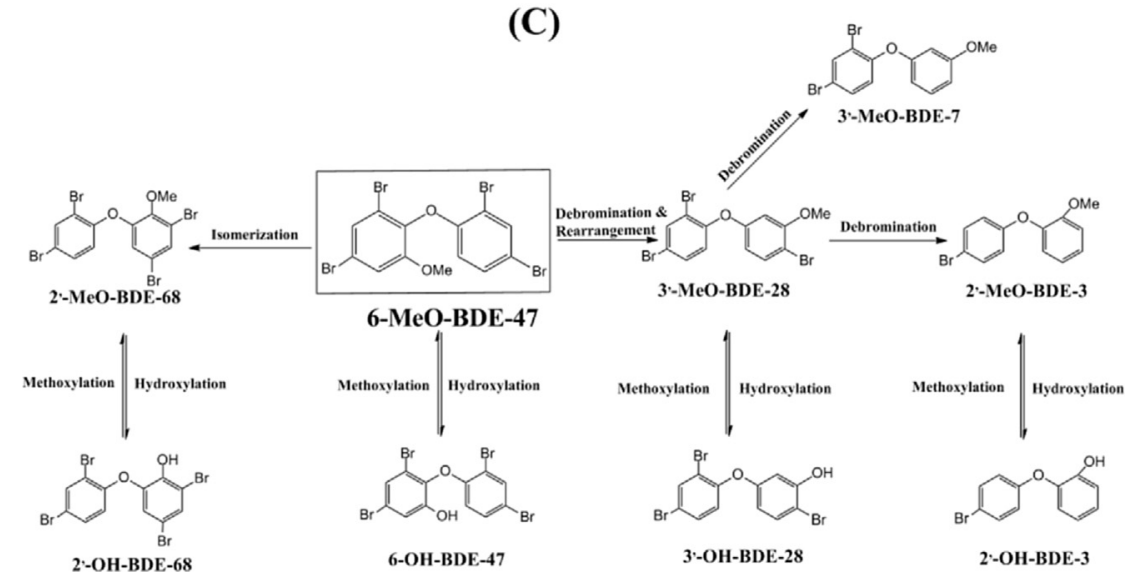

Fig. 3. Metabolic pathways of (A) BDE-47, (B) 6-OH-BDE-47 and (C) 6-MeO-BDE-47 in maize. 
were also expected to occur in maize. Based on the above analysis, brief description of the metabolic pathways of BDE-47, 6-OH-BDE47 and 6-MeO-BDE-47 in maize can be drawn as shown in Fig. 3.

\section{Conclusions}

In summary, BDE-47, 6-OH-BDE-47 and 6-MeO-BDE-47 were accumulated in maize and translocated from roots to shoots over exposure time. Root uptake followed the order: BDE-47 > 6-MeOBDE-47 > 6-OH-BDE-47, while 6-OH-BDE-47 was more prone to acropetal translocation inside maize than BDE-47 and 6-MeO-BDE47. Transformations from BDE-47 to $\mathrm{OH} / \mathrm{MeO}-\mathrm{PBDEs}$, from 6-OHBDE-47 to MeO-PBDEs and from 6-MeO-BDE-47 to OH-PBDEs took place, but there was no transformation from 6-OH-BDE-47 or 6$\mathrm{MeO}-\mathrm{BDE}-47$ to PBDEs in maize. The debromination rate constant for BDE-47 was higher than those of its hydroxylation and methoxylation, thus formation of lower brominated OH-PBDE and MeO-PBDE metabolites from BDE-47 occurred mainly via hydroxylation and methoxylation of the debrominated products of BDE47. Methylation of 6-OH-BDE-47 occurred more rapidly than hydroxylation of 6-MeO-BDE-47 in maize. Besides methylation and hydroxylation, debromination and isomerization were proposed as the potential metabolism pathways to form $\mathrm{MeO}-\mathrm{PBDEs}$ and $\mathrm{OH}-$ PBDEs from 6-OH-BDE-47 and 6-MeO-BDE-47 in maize. The results of this study provide valuable information for a better understanding of the phytoaccumulation and phytotransformation of PBDEs, OH-PBDEs and MeO-PBDEs. Further investigation is necessary to clarify such processes in the natural environment. Moreover, the evidences of analog-specific accumulation and particularly transformation of PBDEs, OH-PBDEs and MeO-PBDEs suggest that precautions should be taken when exploring phytoremediation strategy.

\section{Acknowledgments}

This work was funded by the National Natural Science Foundation of China (Projects 21537005, 21321004 and 21177139), and the Strategic Priority Research Program of the Chinese Academy of Sciences (Grant XDB14020202).

\section{Appendix A. Supplementary data}

Supplementary data related to this article can be found at http:// dx.doi.org/10.1016/j.envpol.2015.10.051.

\section{References}

Boxtel, A.L.V., Kamstra, J.H., Cenijn, P.H., Pieterse, B., Wagner, M.J., Antink, M. Krab, K., Van Der Burg, B., Marsh, G., Brouwer, A., Legler, J., 2008. Microarray analysis reveals a mechanism of phenolic polybrominated diphenylether toxicity in zebrafish. Environ. Sci. Technol. 42 (5), 1773-1779.

California State Senate, 2003-2004. Bill \# AB 302. Available at: http://www/sen.ca. gov/ (accessed 10.09.03.).

Chiou, C.T., Sheng, G.Y., Manes, M., 2001. A partition-limited model for the plant uptake of organic contaminants from soil and water. Environ. Sci. Technol. 35 (7), 1437-1444.

Cox, P., Efthymiou, P., 2003. Directive 2003/11/EC and 76/669/EEC. Off. J. Eur. Union OJ L 42, 45-46.

de Wit, C.A., 2002. An overview of brominated flame retardants in the environment Chemosphere 46, 583-624.

Gandhi, N., Bhavsar, S.P., Gewurtz, S.B., Tomy, G.T., 2011. Can biotransformation of BDE-209 in lake trout cause bioaccumulation of more toxic, lower-brominated PBDEs (BDE-47, -99) over the long term? Environ. Int. 37 (1), 170-177.

Grimm, F.A., Lehmler, H.J., He, X.R., Robertson, L.W., Duffel, M.W., 2013. Sulfated metabolites of polychlorinated biphenyls are high-affinity ligands for the thyroid hormone transport protein transthyretin. Environ. Health Perspect. 121 (6), 657-662.

Hassanin, A., Breivik, K., Meijer, S.N., Steinnes, E., Thomas, G.O., Jones, K.C., 2004 PBDEs in European background soils: levels and factors controlling their distribution. Environ. Sci. Technol. 38 (3), 738-745.
He, J.Z., Robrock, K.R., Alvarez-Cohen, L., 2006. Microbial reductive debromination of polybrominated diphenyl ethers (PBDEs). Environ. Sci. Technol. 40 (14), 4429-4434.

He, Y.H., Murphy, M.B., Yu, R.M.K., Lam, M.H.W., Hecher, M., Giesy, J.P., Wu, R.S.S., Lam, P.K.S., 2008. Effects of 20 PBDE metabolites on steroidogenesis in the H295R cell line. Toxicol. Lett. 176 (3), 230-238.

Huang, H.L., Zhang, S.Z., Christie, P., 2011. Plant uptake and dissipation of PBDEs in the soils of electronic waste recycling sites. Environ. Pollut. 159, 238-243.

Huang, H.L., Zhang, S.Z., Christie, P., Wang, S., Xie, M., 2010. Behavior of decabromodiphenyl ether (BDE-209) in the soil plant system: uptake, translocation, and metabolism in plants and dissipation in soil. Environ. Sci. Technol. 44 (2), 663-670.

Ji, K., Choi, K., Giesy, J.P., Musarrat, J., Takeda, S., 2011. Genotoxicity of several polybrominated diphenyl ethers (PBDEs) and hydroxylated PBDEs, and their mechanisms of toxicity. Environ. Sci. Technol. 45 (11), 5003-5008.

Jin, J., Liu, W.Z., Wang, Y., Tang, X.Y., 2008. Levels and distribution of polybrominated diphenyl ethers in plant, shellfish and sediment samples from Laizhou Bay in China. Chemosphere 71, 1043-1050.

Sandermann, H., 1994. Higher plant metabolism of xenobiotics: the 'green liver' concept. Pharmacogenetics 4 (5), 225-241.

Kelly, B.C., Ikonomou, M.G., Blair, J.D., Gobas, F.A.P.C., 2008. Hydroxylated and methoxylated polybrominated diphenyl ethers in a Canadian Arctic marine food web. Environ. Sci. Technol. 42 (19), 7069-7077.

Kim, U.J., Yen, N.T.H., Oh, J.E., 2014. Hydroxylated, methoxylated, and parent polybrominated diphenyl ethers (PBDEs) in the inland environment, Korea, and potential $\mathrm{OH}$ and MeO-BDE source. Environ. Sci. Technol. 48 (13), 7245-7253.

Lacorte, S., Ikonomou, M.G., 2009. Occurrence and congener specific profiles of polybrominated diphenyl ethers and their hydroxylated and methoxylated derivatives in breast milk from Catalonia. Chemosphere 74 (3), 412-420.

Lai, Y.O. Cai, Z.W., 2012. In vitro metabolism of hydroxylated polybrominated diphenyl ethers and their inhibitory effects on $17 \beta$-estradiol metabolism in rat liver microsomes. Environ. Sci. Pollut. Res. 19 (8), 3219-3227.

Li, F., Li, X.H., Liu, X.L., Zhang, L.B., You, L.P., Zhao, J.M., Wu, H.F., 2011. Noncovalent interactions between hydroxylated polycyclic aromatic hydrocarbon and DNA: molecular docking and QSAR study. Environ. Toxicol. Pharmacol. 32 (3), 373-381.

López, P. Brandsma, S.A., Leonards, P.E.G., de Boer, J., 2009. Methods for the determination of phenolic brominated flame retardants, and by-products, formulation intermediates and decomposition products of brominated flame retardants in water. J. Chromatogr. A 1216 (3), 334-345.

Malmvärn, A., Zebühr, Y., Kautsky, L., Bergman, K., Asplund, L., 2008. Hydroxylated and methoxylated polybrominated diphenyl ethers and polybrominated dibenzo-p-dioxins in red alga and cyanobacteria living in the Baltic Sea. Chemosphere 72 (6), 910-916.

Meerts, I.A.T.M., Letcher, R.J., Hoving, S., Marsh, G., Bergman, K., Lemmen, J.G., van der Burg, B., Brouwer, A., 2001. In vitro estrogenicity of polybrominated diphenyl ethers, hydroxylated PBDEs, and polybrominated bisphenol A compounds. Environ. Health Perspect. 109 (4), 399-407.

Munschy, C., Héas-Moisan, K., Tixier, C., Pacepavicius, G., Alaee, M., 2010. Dietary exposure of juvenile common sole (Solea solea L.) to polybrominated diphenyl ethers (PBDEs): part 2. Formation, bioaccumulation and elimination of hydroxylated metabolites. Environ. Pollut. 158 (12), 3527-3533.

Newton, S., Sellström, U., de Wit, C.A., 2015. Emerging flame retardants, PBDEs, and HBCDDs in indoor and outdoor media in stockholm. Swed. Environ. Sci. Technol. 49, 2912-2920.

Qiu, X.H., Bigsby, R.M., Hites, R.A., 2009. Hydroxylated metabolites of polybrominated diphenyl ethers in human blood samples from the United States. Environ. Health Perspect. 117 (1), 93-98.

Qiu, X.H., Mercado-Feliciano, M., Bigsby, R.M., Hites, R.A., 2007. Measurement of polybrominated diphenyl ethers and metabolites in mouse plasma after exposure to a commercial pentabromodiphenyl ether mixture. Environ. Health Perspect. 115 (7), 1052-1058.

Shang, H.T., Wang, P., Wang, T., Wang, Y.W., Zhang, H.D., Fu, J.J., Ren, D.W., Chen, W.H., Zhang, Q.H., Jiang, G.B., 2013. Bioaccumulation of PCDD/Fs, PCBs and PBDEs by earthworms in field soils of an E-waste dismantling area in China. Environ. Int. 54, 50-58.

Stapleton, H.M., Kelly, S.M., Pei, R., Letcher, R.J., Gunsch, C., 2009. Metabolism of polybrominated diphenyl ethers (PBDEs) by human hepatocytes in vitro. Environ. Health Perspect. 117 (2), 197-202.

Su, G.Y., Yu, H.X., Lam, M.H.W., Giesy, J.P., Zhang, X.W., 2014. Mechanisms of toxicity of hydroxylated polybrominated diphenyl ethers (HO-PBDEs) determined by toxicogenomic analysis with a live cell array coupled with mutagenesis in Escherichia coli. Environ. Sci. Technol. 48 (10), 5929-5937.

Sun, J.T., Liu, J.Y., Yu, M., Wang, C., Sun, Y.Z., Zhang, A.Q., Wang, T., Lei, Z., Jiang, G.B., 2013a. In vivo metabolism of $2,2^{\prime}, 4,4^{\prime}$-tetrabromodiphenyl ether (BDE-47) in young whole pumpkin plant. Environ. Sci. Technol. 47 (8), 3701-3707.

Sun, J.T., Liu, J.Y., Liu, Y.W., Jiang, G.B., 2013b. Levels and distribution of methoxylated and hydroxylated polybrominated diphenyl ethers in plant and soil samples surrounding a seafood processing factory and a seafood market. Environ. Pollut. 176, 100-105.

Sun, J.T., Liu, J.Y., Liu, Y.W., Yu, M., Jiang, G.B., 2014. Reciprocal transformation between hydroxylated and methoxylated polybrominated diphenyl ethers in young whole pumpkin plants. Environ. Sci. Technol. Lett. 1 (4), 236-241.

Tang, Z.W., Huang, Q.F., Cheng, J.L., Yang, Y.F., Yang, J., Guo, W., Nie, Z.Q., Zeng, N., Jin, L., 2014. Polybrominated diphenyl ethers in soils, sediments, and human 
hair in a plastic waste recycling area: a neglected heavily polluted area. Environ. Sci. Technol. 48 (3), 1508-1516.

Teuten, E.L., Xu, L., Reddy, C.M., 2005. Two abundant bioaccumulated halogenated compounds are natural products. Science 307 (5711), 917-920.

Tokarz, J.A., Ahn, M.Y., Leng, J., Filley, T.R., Nies, L., 2008. Reductive debromination of polybrominated diphenyl ethers in anaerobic sediment and a biomimetic system. Environ. Sci. Technol. 42 (4), 1157-1164.

Ueno, D., Darling, C., Alaee, M., Pacepavicius, G., Teixeira, C., Campbell, L., Letcher, R.J., Bergman, K., Marsh, G., Muir, D., 2008. Hydroxylated polybrominated diphenyl ethers (OH-PBDEs) in the abiotic environment: surface water and precipitation from Ontario, Canada. Environ. Sci. Technol. 42 (5), 1657-1664.

Wang, S., Zhang, S.Z., Huang, H.L., Lu, A.X., Ping, H., 2012. Debrominated, hydroxylated and methoxylated metabolism in maize (Zea mays L.) exposed to lesser polybrominated diphenyl ethers (PBDEs). Chemosphere 89 (11), 1295-1301.

Wang, S., Zhang, S.Z., Huang, H.L., Niu, Z.C., Han, W., 2014. Characterization of polybrominated diphenyl ethers (PBDEs) and hydroxylated and methoxylated PBDEs in soils and plants from an e-waste area, China. Environ. Pollut. 184, 405-413.

Wang, S., Wu, T., Huang, H.L., Ping, H., Lu, A.X., Zhang, S.Z., 2011a. Analysis of hydroxylated polybrominated diphenyl ethers in plant samples using ultra performance liquid chromatography-mass spectrometry. Sci. China Chem. 54 (11), $1782-1788$.

Wang, S., Zhang, S.Z., Huang, H.L., Christie, P., 2011b. Behavior of decabromodiphenyl ether (BDE-209) in soil: effects of rhizosphere and mycorrhizal colonization of ryegrass roots. Environ. Pollut. 159, 749-753.

Wang, S., Zhang, S.Z., Huang, H.L., Zhao, M.M., Lv, J.T., 2011c. Uptake, translocation and metabolism of lesser polybrominated diphenyl ethers (PBDEs) and polychlorinated biphenyls (PCBs) in maize (Zea mays L.). Chemosphere 85 379-385.

Wan, Y., Wiseman, S., Chang, H., Zhang, X., Jones, P.D., Hecker, M., Kannan, K. Tanabe, S., Hu, J., Lam, M.H.W., Giesy, J.P., 2009. Origin of hydroxylated brominated diphenyl ethers: natural compounds or man-made flame retardants? Environ. Sci. Technol. 43, 7536-7542.

Wen, B., Huang, R.X., Wang, P., Zhou, Y.P., Shan, X.Q., Zhang, S.Z., 2011. Effect of complexation on the accumulation and elimination kinetics of cadmium and ciprofloxacin in the earthworm eisenia fetida. Environ. Sci. Technol. 45 (10), 4339-4345.

Wiseman, S.B., Wan, Y., Chang, H., Zhang, X.W., Hecker, M., Jones, P.D., Giesy, J.P. 2011. Polybrominated diphenyl ethers and their hydroxylated/methoxylated analogs: environmental sources, metabolic relationships, and relative toxicities. Mar. Pollut. Bull. 63, 179-188.

Xu, X.H., Huang, H.L., Wen, B., Wang, S., Zhang, S.Z., 2015. Phytotoxicity of brominated diphenyl ether-47 (BDE-47) and its hydroxylated and methoxylated analogues (6-OH-BDE-47 and 6-MeO-BDE-47) to maize (Zea mays L.). Chem. Res. Toxicol. 28 (3), 510-517.

Yu, M., Liu, J.Y., Wang, T., Sun, J.T., Liu, R.Z., Jiang, G.B., 2013. Metabolites of 2,4,4'tribrominated diphenyl ether (BDE-28) in pumpkin after in vivo and in vitro exposure. Environ. Sci. Technol. 47 (23), 13494-13501.

Zhang, K., Wan, Y., Jones, P.D., Wiseman, S., Giesy, J.P., Hu, J.Y., 2012. Occurrences and fates of hydroxylated polybrominated diphenyl ethers in marine sediments in relation to trophodynamics. Environ. Sci. Technol. 46 (4), 2148-2155.

Zhu, L.Y., Ma, B.L., Hites, R.A., 2009. Brominated flame retardants in serum from the general population in northern china. Environ. Sci. Technol. 43 (18) 6963-6968. 